\title{
Translator's Acknowledgements
}

want to thank, first of all, Tamara Hundorova, my mentor and colleague, who
entrusted the translation of her book to me. It has been a great pleasure for me, an intellectual challenge, and enormous responsibility. It is an equally pleasant task to thank Harvard Ukrainian Research Institute for this opportunity; in particular, I am grateful to Oleh Kotsyuba and Vitaly Chernetsky for their guidance and attention to my work. Finally, I thank the Academic Studies Press and especially Stuart Allen, the editor of my translation, for his patience, diligence, and inventiveness. 
